\title{
Television Viewing Promoting Obesity in Children: Do We Really Know the Mechanism?
}

Michael Borghese and Jean-Philippe Chaput*

Healthy Active Living and Obesity Research Group, Children's Hospital of Eastern Ontario Research Institute, 401 Smyth Road, Ottawa, ON, Canada

\section{Introduction}

The link between television viewing and overweight and obesity in children has been reported for the first time in the literature, approximately 3 decades ago [1]. This relationship has been echoed in both cross-sectional [2], and longitudinal [3], studies throughout the past $\sim 30$ years. In some studies, screen time has been shown to be more strongly associated with obesity than moderate-to-vigorous physical activity (MVPA) [4]. Several mechanisms have been proposed to explain this relationship, and are discussed herein.

\section{The displacement hypothesis}

The concept of time use displacement with television viewing was identified in the 1960s, when television first emerged [5]. Television viewing has been shown to displace a number of activities, including homework and studying time [6]. The displacement hypothesis of television viewing suggests that an increase in the amount of time spent in this sedentary pursuit directly decreases the amount of discretionary time available for physical activity [5], thus decreasing daily energy expenditure, and leading to a positive caloric balance. This has been a dominant view in the field of sedentary behaviour and obesity research throughout the past decades. The notion that the link between television viewing and obesity is due to a relative lack of physical activity, can be seen in the editor's note of the paper by Gortmaker et al. [3]: "The way to solve this problem is to rig all television sets to generators that must be powered manually - perhaps by a bicycle? Exercise would increase or viewing would decrease; it's guaranteed! " We now know that television viewing time is not necessarily related to time spent in MVPA $[5,7,8]$, and that low levels of screen time do not necessarily predict high levels of MVPA [9]. The displacement hypothesis seems an unlikely candidate as a mechanism for explaining the relationship between television viewing and obesity, as children can be 'active couch potatoes'-they can obtain both high amounts of sedentary time, as well as high amounts of MVPA throughout the day [10]. Furthermore, if the association between television viewing and obesity is solely due to the sedentary nature of television viewing, then we would expect that total sedentary time would be associated with obesity in children; however, this has not been shown to be the case in many studies [11]. Recently, Mitchell et al. [12] found that total sedentary time was associated with an increase in body mass index (BMI), but only after adjusting for time spent in MVPA.

\section{Reduction in resting metabolic rate}

It is said that television watching may decrease a child's metabolic rate [13], thus leading to a decrease in total energy expenditure and a positive caloric balance. The evidence to support this mechanism is however limited. Klesges et al. [14] found that the metabolic rate of children was lower when they were watching television than when they were at rest. However, Dietz et al. [15] found that resting metabolic rate did not change with television viewing, as compared to reading or sitting quietly, which is consistent with findings in adults [16]. Dietz et al. [15] also found that children tended to fidget more when they were sitting quietly, than when they were reading or watching television
[15]. Further research is needed to rule out whether or not a reduction in metabolic rate seen with television viewing has anything do with television viewing itself, or with a lack of fidgeting with children being occupied by other activities. While this potential mechanism cannot be ruled out as a potential explanation, at least in part, for the relationship between television viewing and obesity in children, caution should be exercised in interpreting these results, until more evidence is available.

\section{Television content and food choices}

Television viewing differs from other sedentary behaviours, in that it offers an avenue for food marketers to advertise their products to potential consumers. In fact, in 1990, food advertisements constituted 9.6 minutes of programming time per hour in the United States [17]. In 2005, out of 275 foods advertised during children's television programs, $83 \%$ were convenience/fast foods or sweets, and betweenmeal snacking was depicted more often than breakfast, lunch, and dinner combined [18]. While television advertisements have the capacity to influence food choices and preferences, in order to influence obesity these preferences must be acted upon-children must actually consume these foods. Television advertisements have been shown to increase total food intake, by up to $45 \%$ in children in experimental studies [19]. Furthermore, food intake has been shown to increase for each additional hour of television watched $[2,20]$, and children who watch more television were more likely to consume sweets and soft drinks, and less likely to consume fruits and vegetables [21,22]. This is not surprising, as a number of sedentary behaviours have been associated with an overconsumption of food in our current obesogenic environment $[23,24]$. While television watching has been shown to increase food intake throughout the whole day, food intake has also been shown to increase, while children are watching television.

\section{Increased food intake through between-meal snacking}

Eating in front of the television has been suggested to be one of the major mechanisms behind the relationship between television viewing and obesity in children. Up to $26 \%$ of total energy intake may be consumed in front of the television [25]. Furthermore, intervention studies have shown that reductions in sedentary behaviour can lead to reductions in BMI z-scores, and that this may be mediated by less food intake, rather than more MVPA [26]. Increased food intake while watching television is thought to be driven by several

${ }^{*}$ Corresponding author: Jean-Philippe Chaput, Healthy Active Living and Obesity Research Group, Children's Hospital of Eastern Ontario Research Institute, 401 Smyth Road, Ottawa, ON, K1H 8L1, Canada, Tel: +1 613737 7600, ext. 4191; Fax: +1 613738 4800; E-mail: mborghese@cheo.on.ca

Received April 06, 2013; Accepted April 08, 2013; Published April 15, 2013

Citation: Borghese M, Chaput JP (2013) Television Viewing Promoting Obesity in Children: Do We Really Know the Mechanism? Bioenergetics 2: e113. doi:10.4172/2167-7662.1000e113

Copyright: (c) 2013 Borghese M, et al. This is an open-access article distributed under the terms of the Creative Commons Attribution License, which permits unrestricted use, distribution, and reproduction in any medium, provided the original author and source are credited. 
distraction mechanisms: an attention allocation to TV stimulus [27,28], habituation to food cues through food [29], and non-food stimuli [30], and distraction leading to delayed and reduced satiety signals [27]. As noted by Thivel et al. [23], there is currently no definitive evidence to understand, how children who are overweight/obese or of normal weight may differ in their food intake patterns in front of the television. In a society where television viewing is ubiquitous, alongside other obesogenic behaviors and environmental factors, a reduction in the frequency of food consumption in front of the screen, may go a long way in the prevention of obesity in children.

\section{Conclusion}

Television viewing may represent an important area of intervention for the prevention of obesity in children. There are four proposed mechanisms underlying the relationship between television viewing and obesity in children: 1) the displacement hypothesis, 2) reduction in resting metabolic rate, 3) television content and food choices, and 4) between-meal snacking in front of the television. The popular notion that television viewing causes obesity through a displacement of physical activity is not supported by the available evidence. Additionally, there is very little evidence to conclude that television viewing is associated with a reduction in resting metabolic rate, at least beyond that seen with other sedentary behaviors. However, the literature supports the latter 2 mechanisms, in that television content does influence food choices in children, and that distraction mechanisms while watching television may promote increased caloric intake through between-meal snacking. Future research should focus on how children who are overweight and obese differ from their normal-weight counterparts in their television viewing and associated food intake patterns. Moreover, intervention studies looking at the influence of reducing television viewing time on daily food intake should examine whether the effect is similar or not between obese and lean children. Given that television viewing is pervasive in modern societies, efforts aiming to minimize the adverse effects of this sedentary behaviour on health are warranted.

\section{Acknowledgements}

Mr. Borghese is supported by a graduate bursary from the Healthy Active Living and Obesity Research Group, as well as an Admission Scholarship from the University of Ottawa. Dr. Chaput holds a Junior Research Chair in Healthy Active Living and Obesity Research.

\section{References}

1. Dietz WH, Gortmaker SL (1985) Do we fatten our children at the television set? Obesity and television viewing in children and adolescents. Pediatrics 75 : 807-812

2. Crespo CJ, Smit E, Troiano RP, Bartlett SJ, Macera CA, et al (2001) Television watching, energy intake, and obesity in US children. Arch Pediatr Adolesc Med 155: 360-365.

3. Gortmaker SL, Must A, Sobol AM, Peterson K, Colditz GA, et al. (1996) Television viewing as a cause of increasing obesity among children in the united states, 1986-1990. Arch Pediatr Adolesc Med 150: 356-362.

4. Eisenmann JC, Bartee RT, Wang MQ (2002) Physical activity, TV viewing, and weight in US youth: 1999 Youth Risk Behaviour Survey. Obes Res 10: 379-385.

5. Mutz DC, Roberts DF, Vuuren DP (1993) Reconsidering the displacement hypothesis: Television's influence on children's time use. Commun Res 20: 51 75.

6. Hornik R (1981) Out-of-school television and school: Hypotheses and methods. Rev Educ Res 51: 193-214.

7. Ekelund U, Brage S, Froberg K, Harro M, Anderssen SA, et al. (2006) TV viewing and physical activity are independently associated with metabolic risk in children: the European Youth Heart Study. PLoS Med 3: e488.
8. Biddle SJH, Gorely T, Marshall SJ, Murdey I, Cameron N (2003) Physical activity and sedentary behaviours in youth: issues and controversies. Perspect Public Health 124: 29-33.

9. Fakouri THI, Hughes JP, Brody DJ, Kit BK, Ogden CL (2013) Physical activity and screen-time viewing among elementary school-aged children in the United states from 2009 to 2010 . JAMA Pediatr 167: 223-229.

10. Katzmarzyk PT, Church TS, Craig CL, Bouchard C (2009) Sitting time and mortality from all causes, cardiovascular disease, and cancer. Med Sci Sports Exerc 41: 998-1005.

11. Byun W, Liu J, Pate RR (2013) Association between objectively measured sedentary behaviour and body mass index in preschool children. Int $\mathrm{J}$ Obes (Lond).

12. Mitchell JA, Pate RR, Beets MW, Nader PR (2013) Time spent in sedentary behaviour and changes in childhood BMl: a longitudinal study from ages 9 to 15 years. Int J Obes (Lond) 37: 54-60.

13. Bryant MJ, Lucove JC, Evenson KR, Marshall S (2007) Measurement of television viewing in children and adolescents: a systematic review. Obes Rev 8: 197-209.

14. Klesges RC, Shelton ML, Klesges LM (1993) Effects of television on metabolic rate: potential implications for childhood obesity. Pediatrics 9: 281-286.

15. Dietz WH, Bandini LG, Morelli JA, Peers KF, Ching PLYH (1994) Effect of sedentary activities on resting metabolic rate. Am J Clin Nutr 59: 556-559.

16. Buchowski MS, Sun M (1996) Energy expenditure, television viewing and obesity. Int J Obes Relat Metab Disord 20: 236-244.

17. Story M, Faulkner P (1990) The prime time diet: A context analysis of eating behaviour and food messages in television program content and commercials. Am J Public Health 80: 738-740.

18. Harrison K, Marske AL (2009) Nutritional content of foods advertised during the television programs children watch most. Am J Public Health 95: 1568-1574.

19. Harris JL, Bargh JA, Brownell KD (2009) Priming effects of television food advertising on eating behaviour. Health Psychol 28: 404-413.

20. Sonneville KR, Gortmaker SL (2008) Total energy intake, adolescent discretionary behaviors and the energy gap. Int J Obes (Lond) 32: S19-S27.

21. Santaliestra-Pasias AM, Mouratidou T, Verbestel V, Huybrechts I, Gottrand F, et al. (2012) Food consumption and screen-based sedentary in European adolescents. The HELENA study. Arch Pediatr Adolesc Med 166: 1010-1020.

22. Vereecken CA, Todd J, Roberts C, Mulvihill C, Maes L (2006) Television viewing behaviour and associations with food habits in different countries. Public Health Nutr 9: 244-250.

23. Thivel D, Tremblay MS, Chaput JP (2013) Modern sedentary behaviours favo energy consumption in children and adolescents. Curr Obes Rep 2: 50-57.

24. Chaput JP, Klingenberg L, Astrup A, Sjodin AM (2011) Modern sedentary activities promote overconsumption of food in our current obesogenic environment. Obes Rev 12: e12-e20.

25. Matheson DM, Killen JD, Wang Y, Varady A, Robinson TN (2004) Children's food consumption during television viewing. Am J Clin Nutr 79: 1088-1094

26. Epstein LH, Roemmich JN, Robinson JL, Paluch RA, Winiewicz DD, et al (2008) A randomized trial of the effects of reducing television viewing and computer use on body mass index in young children. Arch Paediatr Adolesc Med 162: 239-245.

27. Bellisle F, Dalix AM, Slama G (2004) Non food-related environmental stimul induce increased meal intake in healthy women: a comparison of television viewing versus listening to a recorded story in laboratory setting. Appetite 43 : $175-180$.

28. Stroebele N, de Castro JM (2004) Television viewing is associated with an increase in meal frequency in humans. Appetite 42: 111-113.

29. Temple JL, Kent KM, Giacomelli AM, Paluch RA, Roemmich JN, et al. (2006) Habituation and recovery of salivation and motivated responding for food in children. Appetite 46: 280-284.

30. Epstein LH, Saad FG, Giacomelli AM, Roemmich JN (2005) Effects of allocation of attention on habituation to olfactory and visual food stimuli in children. Physiol Behav 84: 313-319. 